tổn thương ngắn (dưới $1 \mathrm{~cm}$ ) (Hình 2). Ngoài ra nếu lựa chọn ghép đoạn bằng tĩnh mạch hiển thì cũng rất khó khăn vì kích thước tĩnh mạch này ở trẻ em rất nhỏ, không thể sử dụng được. Tuy nhiên ở trẻ lớn, khi kích thước tĩnh mạch đủ lớn, có thể sử dụng kĩ thuật ghép đoạn động mạch khi tổn thương thành mạch dài, tránh bỏ sót tổn thương dẫn tới tắc mạch sau mổ. Trong nghiên cứu này, có 2 trường hợp sử dụng tĩnh mạch hiển tự thân để ghép đoạn, đều là các trẻ lớn, trên 8 tuổi.
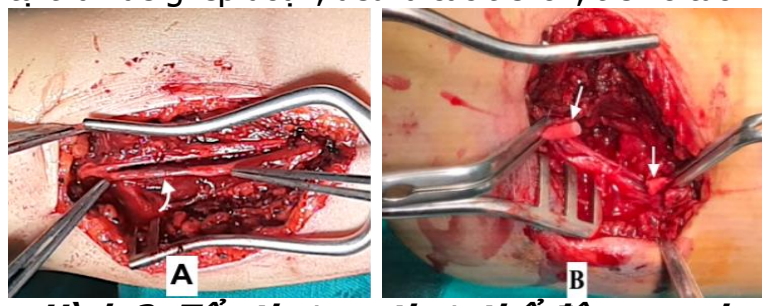

Hình 2: Tôn thương thức thể đông mach cánh tay và xử trí phẫu thuật (stt 31)

A. Đụng dập, huyêt khối, đứt gần rời động mạch cánh tay, B. Cắt đoạn mạch tôn thương, nối trực tiếp

Sau mổ hầu hết các bệnh nhi đều được phục hồi lưu thông mạch máu chi với kết quả tốt: tay hồng ấm, mạch quay bắt rõ, siêu âm kiểm tra có phổ mạch và tốc độ dòng chảy tốt. Tuy nhiên có 2 trường hợp bi tắc mạch phải phẫu thuật lại (Bảng 6). Nguyên nhân gây tắc ngoài việc không cắt bỏ hết tổn thương, còn có thể do kĩ thuật làm miệng nối bị hẹp hoặc sử dụng thuốc chống đông. Cả hai trường hợp này sau đó đều ra viện với kết quả tốt.

\section{KẾT LUÂ̂N}

Đa phần gãy trên lồi cầu có tổn thương động mạch cánh tay không có triệu chứng thiếu máu chi cấp tính giống như chấn thương động mạch ngoại vi ở người lớn, do đó không cần xử trí phục hồi lưu thông mạch máu cấp cứu cho mọi trường hợp. Việc chẩn đoán rất cần phối hợp giữa lâm sàng, siêu âm và cắt lớp vi tính để xác định chính xác tổn thương. 53,6\% trường hợp tổn thương co thắt động mạch liên quan tới ổ gãy xương, nhưng không có thương tổn thực thể thành mạchhoặc trong lòng động mạch cánh tay. Phẫu thuật vẫn là phương pháp quyết định để chẩn đoán tổn thương và phục hồi lưu thông mạch máu.

\section{TÀI LIÊU THAM KHẢO}

1. Phan Quang Trí (2014). Gãy trên hai lồi cầu xương cánh tay ở trẻ em có tổn thương mạch máu và hội chứng Volkmann. Tạp chí Y học thực hành, 903, 82-83.

2. Abzug J.M. and Herman M.J. (2012) Management of supracondylar humerus fractures in children: current concepts. J Am Acad Orthop Surg, 20(2), 69-77.

3. Sharma S., Singh V.P., and Bera S. (2019). Brachial artery injury in pediatric patients: review of management and outcome in 29 patients. Int Surg J, 6(12), 4419.

4. Usman R., Jamil M., and Hashmi J.S. (2017). Management of Arterial Injury in Children with Supracondylar Fracture of the Humerus and a Pulseless Hand. Ann Vasc Dis, 10(4), 402-406.

5. Rehman Z.U., Riaz A., and Nazir Z. (2020). Peripheral Arterial Injuries in Children: An Audit at a University Hospital in Developing Country. Ann Vasc Dis, 13(2), 158-162.

6. David S, Flynn J.M (2014). The pediatric upper extremity, Spinger, New York.

7. Phan Quang Trí (2016). Nghiên cứu điều trị gãy trên lồi cầu xương cánh tay kiểu duỗi ở trẻ em bằng nắn kín và xuyên kim qua da dưới màn tăng sáng., Luận án tiến sĩ, Đại học Y Dược Thành phố Hồ Chí Minh.

\title{
KHẢO SÁT RỐI LOẠN DẠ DÀY RUỘT Ở BỆNH NHÂN THÂ̂N NHÂN TẠO CHU KỲ TẠI BÊ̂NH VIÊ̂N ĐA KHOA KHU VỰC THÜ ĐỨC
}

\author{
Đào Bùi Quý Quyền ${ }^{1}$, Nguyễn Thị Bé2, Lê Việt Thắng ${ }^{2}$
}

\section{TÓM TẮT}

Mục tiêu: Xác định đặc điểm rối loạn dạ dày ruột theo bảng điểm Gastrointestinal Symptom Rating

\footnotetext{
${ }^{1}$ Bệnh viện Chợ rẫy, TP Hồ Chí Minh

${ }^{2}$ Học viện Quân y

Chịu trách nhiệm chính: Lê Việt Thắng

Email: lethangviet@yahoo.com.uk

Ngày nhận bài: 13/4/2021

Ngày phản biện khoa học: 8/5/2021

Ngày duyệt bài: 21/5/2021
}

Scale-GSRSở bệnh nhân bệnh thận mạn giai đoạn cuối thận nhân tạo chu kỳ. Đối tượng và phương pháp: Nghiên cứu cắt ngang trên 80 bệnh nhân thận nhân tạo chu kỳ. Tất cả các bệnh nhân điều được hỏi tình trạng rối loạn dạ dày ruột theo bảng điểm GSRS. Kết quả: Điểm GSRS trung bình là $8(2,25$ - 13), có $80 \%$ bệnh nhân xuất hiện ít nhất 01 triệu chứng dạ dày ruột. Nhóm bệnh nhân tuổi $\geq 60$; lọc máu $\geq 10$ năm có chỉ số GSRS trung bình cao hơn nhóm không có đặc điểm trên, $p<0,01$. Có mối tương quan nghịch điểm GSRS với nồng độ hemoglobin và albumin máu, $\mathrm{p}<0,01$. Kết luận: Rối loạn dạ dày ruột là thường 
gặp và có liên quan đến tuổi cao, thời gian lọc máu dài và suy dinh dưỡng ở bệnh nhân thận nhân tạo chu kỳ.

Tư khóa: Thận nhân tạo chu kỳ, tỷ lệ triệu chứng dạ dày ruột, suy dinh dưỡng.

\section{SUMMARY \\ SURVEY ON GASTROINTESTINAL DISORDERS IN THE PATIENTS TREATING WITH MAINTENANCE HEMODIALYSIS AT THU DUC AREA GENERAL HOSPITAL}

Objectives: To determinegastrointestinal disorders according to the Gastrointestinal Symptom Rating Scale-GSRS in patients with end stage chronic kidney disease treating with maintenance maintenance hemodialysis. Subjects and Methods: Cross-sectional study on 80 regular hemodialysis patients. All patients were asked about gastrointestinal disorders according to the GSRS score. Results: The median GSRS score was 8 (2.25 - 13), $80 \%$ of patients had at least one gastrointestinal symptom. Group of patients $\geq 60$ years old; dialysis $\geq 10$ years, the median GSRS index was higher than the group without the above characteristics, $p<0.01$. There is a negative correlation between GSRS and hemoglobin; serum albumin levels, $\mathrm{p}<0.01$. Conclucsion: Gastrointestinal disturbances are common and are associated with old age, long dialysis duration, and malnutrition in patients with regular hemodialysis.

Keywords: Maintenance Hemodialysis, Gastrointestinal Symptom Rating Scale-, malnutrition.

\section{I. ĐĂT VẤN ĐỀ}

Tổn thương ống và tuyến tiêu hoá thường gặp ở bệnh nhân bệnh thận mạn tính các giai đoạn bao gồm cả bệnh nhân lọc máu chu kỳ với các mức độ khác nhau [1],[2]. Các biểu hiện về da dày- tá tràng như đau thượng vị, ơ hơi, ơ chua, buồn nôn, nôn, đi cầu phân lỏng nhiều khi gây khó khăn cho quá trình lọc máu, cũng như điều trị suy thận mạn tính nói chung. Các triệu chứng tiêu hoá thường đa dạng, xác định dễ dàng, tuy nhiên cần được lượng hoá để đánh giá mức độ rối loạn tiêu hoá. Bảng điểm tỷ lệ các triệu chứng dạ dày ruột (Gastrointestinal Symptom Rating Scale - GSRS) là một bảng điểm được sử dụng rộng rãi trong thực hành lâm sàng để đánh giá tần xuất và mức độ xuất hiện các triệu chứng tiêu hoá trên bệnh nhân suy thận mạn tính bao gồm cả chưa lọc máu và đang lọc máu. TheoDong R. và cộng sự (2014), tỷ lệ triệu chứng dạ dày ruột ở bệnh nhân bệnh thận mạn tính giai đoạn cuối có lọc máu chu kỳ chiếm từ $65 \%$ đến $82 \%$, các triệu chứng thường gặp là táo bón, đau bụng, tiêu chảy [2]. Các yếu tố liên quan đến các triệu chứng trên đường tiêu hóa được xác định gồm: thay đổi huyết động, mất chức năng bảo tồn còn lại của thận, lọc máu không đủ... Xuất phát từ những lý do trên, chúng tôi thực hiện đề tài này với mục tiêu: Khảo sát đặc điểm rối loạn tiêu hoá bằng thang điểm tỷ lệ các triệu chứng dạ dày ruột ở bệnh nhân thận nhân tạo chu kỳ tại Bệnh viện đa khoa khu vực Thủ Đức.

\section{II. ĐốI TƯợNG VÀ PHƯƠNG PHÁP NGHIÊN CứU}

1. Đối tượng nghiên cứu: Đối tượng là 80 bệnh nhân bệnh thận mạn tính (BTMT) giai đoạn cuối được lọc máu bằng thận nhân tạo chu kỳ, tại Khoa Thận tiết niệu, Bệnh viện đa khoa khu vực Thủ Đức. Thời gian nghiên cứu từ tháng 4/2020 đến tháng 4/2021.

- Tiêu chuẩn chọn bệnh nhân:

+ Bệnh nhân bệnh thận mạn tính giai đoạn cuối lọc máu bằng TNT chu kỳ

+ Thời gian lọc máu > 3 tháng.

+ Các bệnh nhân được lọc máu đủ tuần 3 lần, mỗi lần 4 giờ, đảm bảo hiệu quả lọc $\mathrm{Kt} / \mathrm{V}>1,2$.

+ Các bệnh nhân đều được áp dụng theo một phác đồ điều trị thống nhất về chế độ lọc máu, điều trị thiếu máu, điều trị tăng huyết áp...

+ Bệnh nhân đồng ý tham gia nghiên cứu

- Tiểu chuẩn loại trừ bệnh nhân:

+ Bệnh nhân tại thời điểm nghiên cứu nghi ngờ mắc bệnh ngoại khoa.

+ Bệnh nhân viêm nhiễm nặng như viêm phổi, viểm tuỵ cấp...

+ Các bệnh nhân không đủ tiêu chuẩn nghiên cứu.

2. Phương pháp nghiên cứu

- Nghiên cứu mô tả, cắt ngang nhóm bệnh nhân nghiên cứu.

- Tính cõ mẫu theo công thức:

$$
N=\frac{\left(Z_{1-a / 2}\right)^{2} \times p(1-p)}{D^{2}}
$$

Trong đó: $Z=1,96$, với độ tin cậy là $95 \%$ $\mathrm{p}=0,89$ (giá trị thấp nhất tỷ lệ ở các nghiên cứu trước); $\mathrm{D}=0,1$, độ chính xác mong muốn.

Theo cách tính, tối thiểu nghiên cứu phải có 65 bệnh nhân.Trong nghiên cứu chúng tôi có 80 bệnh nhân đủ tiêu chuẩn nghiên cứu.

-Bệnh nhân được hỏi bệnh sử, khám lâm sàng. Các xét nghiệm cận lầm sàng bao gồm: xét nghiệm công thức máu, sinh hoá máu các chỉ số: glucose, ure, creatinine, albumin, protein..

-Tất cả các bệnh nhân đều được phỏng vấn, khai thác theo bộ câu hỏi GSRS bao gồm 15 phần trong 5 triệu chứng: trào ngược 2 câu, đau bụng 3 câu, khó tiêu 4 câu, tiêu chảy 3 câu và táo bón 3 câu [3].

3. Xử lý số liệu: Số liệu được xử lý bằng thuật toán thống kê y sinh học theo chương trình SPSS 20.0 


\section{KẾT QUẢ NGHIÊN CỨU}

Tuổi trung bình $53,55 \pm 14,72$, tỷ lệ nam là $45,0 \%$, nữ chiếm $55,0 \%$. Nhóm nghiên cứu có thời gian TNT trung bình là $46(13-76)$ tháng. Điểm GSRS trung bình là $8(2,25$ - 13), thấp nhất là 0 điểm, cao nhất là 33 điểm.

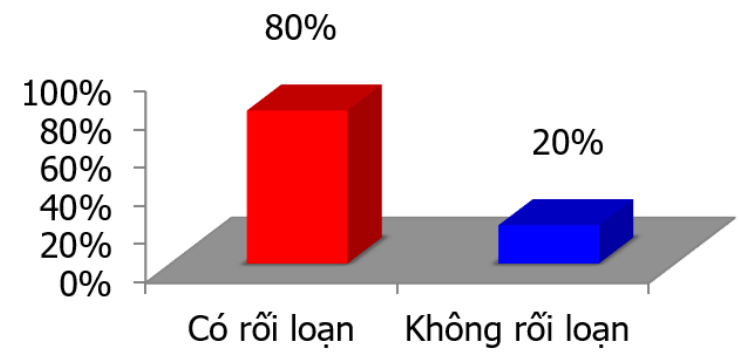

Biểu đồ 1. Tỷ lệ bệnh nhân có ít nhất 1 biểu hiện rối loạn dạ dày ruột (Ti̛' 1 điểm đến 30 điểm)

Nhận xét: Tỷ lể bệnh nhân có rối loạn ít nhất 01 triệu chứng dạ dày ruột cao, chiếm tới $80 \%$.

Bảng 1. Tỷ lệ bệnh nhân theo các nhóm triệu chứng rối loạn

\begin{tabular}{|c|c|c|}
\hline Triệu chứng & Số BN & Tỷ lệ (\%) \\
\hline Đau bụng & 60 & 75,0 \\
\hline Trào ngược & 52 & 65 \\
\hline Khó tiêu & 64 & 80 \\
\hline Tiêu chảy & 20 & 25,0 \\
\hline Táo bón & 11 & 13,8 \\
\hline
\end{tabular}

Phân bố bệnh nhân theo các nhóm triệu chứng rối loạn không đồng đều.Chiếm tỷ lệ cao nhất là biểu hiện khó tiêu, tiếp đến là đau bụng, và trào ngược, tiêu chảy chiếm $1 / 4$ số bệnh nhân và táo bón chỉ chiếm 13,8\%.

Bảng 2. Tỷ lệ bệnh nhân theo mức độ rôi loạn tiêu hoá của thang điểm GSRS $(n=64)$

\begin{tabular}{|c|c|c|}
\hline Mức độ & $\begin{array}{c}\text { Số } \\
\text { BN }\end{array}$ & $\begin{array}{c}\text { Tỷ lệ } \\
(\mathbf{\%})\end{array}$ \\
\hline Nhẹ (0 <GSRS $\leq 15$ điếm) & 47 & 73,4 \\
\hline Vừa (15 < GSRS $\leq 30$ điểm) & 12 & 18,8 \\
\hline Nặng (GSRS > 30 điếm) & 5 & 7,8 \\
\hline
\end{tabular}

Phần bố bênh nhân theo mức độ rối loạn tiêu hoá không đồng đều, chủ yếu mức độ nhẹ chiếm tới 73,4\%. Số bệnh nhân rối loạn mức độ nặng chỉ chiếm $7,8 \%$, còn lại $18,8 \%$ rối loạn mức độ vứa.

Bảng 3. Liên quan GSRS với tuổi và giới

\begin{tabular}{|c|c|c|c|}
\hline \multicolumn{2}{|c|}{ Đặc điểm } & \multirow{2}{*}{$\begin{array}{c}\begin{array}{c}\text { Số bệnh } \\
\text { nhẩn }\end{array} \\
34 \\
\end{array}$} & \multirow{2}{*}{$\begin{array}{l}\text { Tỷ lệ } \\
(\%) \\
77,3\end{array}$} \\
\hline \multirow[b]{2}{*}{$\begin{array}{c}N \tilde{u}^{\prime} \\
(n=44)\end{array}$} & Có rối loạn & & \\
\hline & $\begin{array}{l}\text { Trung vị (Tứ } \\
\text { phân vị) }\end{array}$ & \multicolumn{2}{|c|}{$8(2,25-16)$} \\
\hline \multirow{2}{*}{$\underset{(n=36)}{\operatorname{Nam}}$} & Có rối loạn & 30 & 83,3 \\
\hline & $\begin{array}{c}\text { Trung vị (Tứ } \\
\text { phân vị) }\end{array}$ & \multicolumn{2}{|c|}{$8(2,5-12,75)$} \\
\hline & $\mathrm{p}$ & \multicolumn{2}{|c|}{$>0,05$} \\
\hline
\end{tabular}

\begin{tabular}{|c|c|c|c|}
\hline \multirow{2}{*}{$\begin{array}{c}\geq 60 \\
\text { tuổi } \\
(n=31)\end{array}$} & \multirow{2}{*}{$\begin{array}{c}\text { Có rối loạn } \\
\text { Trung vị (Tứ } \\
\text { phân vị) }\end{array}$} & 28 & 90,3 \\
\hline & & \multicolumn{2}{|c|}{$13(8-18)$} \\
\hline \multirow{2}{*}{$\begin{array}{c}<60 \\
\text { tuổi } \\
(n=49)\end{array}$} & Có rối loạn & 36 & 73,5 \\
\hline & $\begin{array}{l}\text { Trung vị (Tứ } \\
\text { phân vị) }\end{array}$ & \multicolumn{2}{|c|}{$6(0-9,5)$} \\
\hline
\end{tabular}

Không có mối liên quan điếm GSRS với giới, tuy nhiên bệnh nhân tuổi cao có chỉ số GSRS cao hơn nhóm tuổi $<60$ có ý nghĩa, $\mathrm{p}<0,001$.

Bảng 4. Liên quan với thời gian thận nhân tạo

\begin{tabular}{|c|c|c|c|}
\hline \multicolumn{2}{|c|}{ Đặc điểm } & Số bệnh & Tỷ lề \\
\hline \multirow{2}{*}{$\begin{array}{c}<5 \text { năm } \\
(\mathrm{n}=51)\end{array}$} & Có rối loạn & 42 & 82,4 \\
\hline & $\begin{array}{l}\text { Trung vị } \\
\text { (Tứ phân vị) }\end{array}$ & \multicolumn{2}{|c|}{$8(2-13)$} \\
\hline \multirow{2}{*}{$\begin{array}{l}5 \text { đến < } \\
10 \text { năm } \\
(n=20)\end{array}$} & Có rối loạn & 13 & 65,0 \\
\hline & $\begin{array}{l}\text { Trung vị } \\
\text { (Tứ phẩn vị) }\end{array}$ & \multicolumn{2}{|c|}{$7,5(0-10,75)$} \\
\hline \multirow{2}{*}{$\begin{array}{l}\geq 10 \\
\text { năm } \\
(n=9)\end{array}$} & Có rối loạn & 9 & 100,0 \\
\hline & $\begin{array}{l}\text { Trung vị } \\
\text { (Tứ phân vị) }\end{array}$ & \multicolumn{2}{|c|}{$17(12,5-19,5)$} \\
\hline \multicolumn{2}{|c|}{ p giá trị trung bình } & \multicolumn{2}{|c|}{$<0,01$} \\
\hline
\end{tabular}

Các bênh nhân loc máu từ 10 năm trở lên đều có rối loạn dạ dày ruột, điểm GSRS trung bình cao hơn nhóm lọc máu thời gian ngắn hơn, $\mathrm{p}<0,01$.

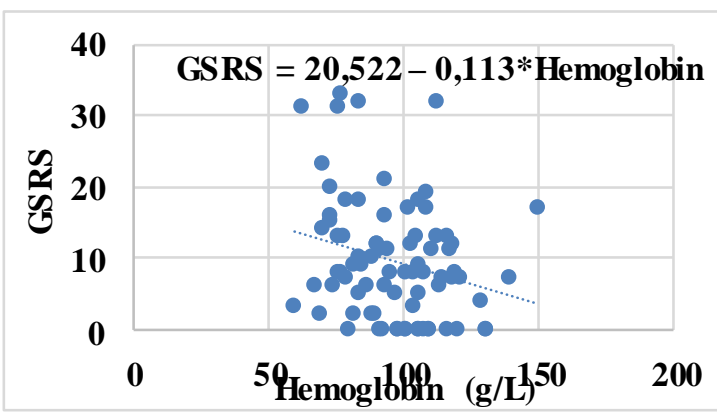

Biểu đồ 2. Tương quan giữa GSRS và Hemoglobin $(n=80)$

Nhận xét: Có mối tương quan nghịch giữa hemoglobin và chỉ số GSRS có ý nghĩa, $r=-0,252$, $\mathrm{p}<0,05$.

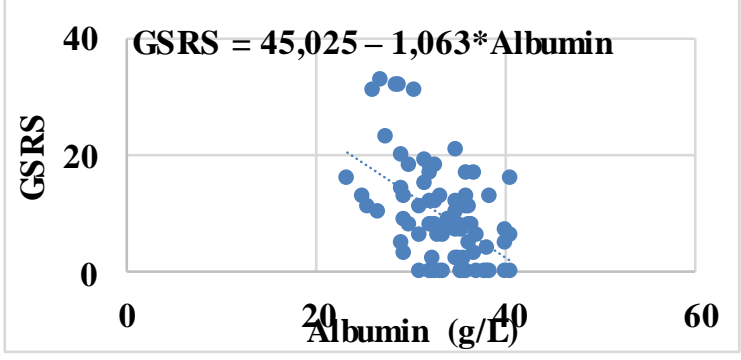

Biểu đồ 3. Tương quan giữa GSRS và Albumin $(n=80)$ 
Nhận xét: Có mối tương quan nghịch giữa nồng độ albumin máu và chỉ số GSRS có ý nghĩa, $r=-0,49, p<0,001$.

\section{BÀN LUÂNN}

1. Đặc điểm rối loạn dạ dày ruột ở bệnh nhân thận nhân tạo chu kỳ: Sử dụng bảng điểm GSRS để đánh giá tình trạng rối loạn dạ dày ruột được nhiều tác giả đã công bố trên các đối tượng bệnh nhân bệnh thận mạn tính. Kết quả nghiên cứu của chúng tôi cho thấy có tới
80\% bệnh nhân có ít nhất 01 triệu chứng rối loạn, trong đó khó tiêu, đau bụng và trào ngược là các triệu chứng có tỷ lệ bệnh nhân cao nhẩt. Tuy nhiên, phân bố bệnh nhẩn theo mức độ rối loạn tiêu hoá không đồng đều, chủ yếu mức độ nhẹ chiếm tới 78,8\%. Số bệnh nhân rối loạn mức độ nặng chỉ chiếm 6,2\%, còn lại $15 \%$ rối loạn mức độ vừa. Khi so sánh với các tác giả trong và ngoài nước chúng tôi cũng có sự tương đồng về kết quả.

Bảng 5. So sánh đặc điểm rôi loạn theo GSRS giữa các nghiên cứu

\begin{tabular}{|c|c|c|c|}
\hline Tác giả & Đối tượng & Tỷ lệ rối loạn & GSRS trung bình \\
\hline $\begin{array}{l}\text { Dong R. và cộng sự } \\
\text { năm } 2014 \text { [2] }\end{array}$ & $\begin{array}{c}\text { - } 294 \text { BN loc máu chu kỳ trong đó } \\
\text { có: } 182 \text { BN TNT và } 112 \text { BN lọc } \\
\text { màng bung }\end{array}$ & $\begin{array}{l}\text { - Nhóm LMB: 61,6\% } \\
\text { - Nhóm TNT: 76,4\%. }\end{array}$ & - \\
\hline $\begin{array}{c}\text { Daniels G. và cộng sự } \\
\text { năm } 2015 \text { [4] }\end{array}$ & $\begin{array}{c}-120 \text { BN bênh thận mạn TNT chu } \\
\text { kỳ tuổi TB } 60 \text { tuổi }\end{array}$ & $\begin{array}{l}\text { Tỷ lệ BN có ít nhất } 01 \\
\text { triệu chứng: } 90 \%\end{array}$ & - \\
\hline $\begin{array}{l}\text { Mitrovic M. và cộng } \\
\text { sự năm 2015[5்] }\end{array}$ & $\begin{array}{c}\text { - } 245 \text { BN bênh thận mạn giai đoạn } \\
5 \text { trong đó } 173 \text { TiNT chu kỳ và } 72 \\
\text { lọc màng bụng }\end{array}$ & $\begin{array}{l}\text { Tỷ lệ BN có ít nhất } 01 \\
\text { triệu chứng: TNT là } \\
\text { 91,3\%, LMB: } 100 \% \text {. }\end{array}$ & - \\
\hline $\begin{array}{l}\text { Lê Xuân Bách và cộng } \\
\text { sự năm } 2015 \text { [6] }\end{array}$ & $\begin{array}{c}\text { - } 124 \text { bệnh nhân bênh thận mạn } \\
\text { giai đoạn } 5 \text { trong đó có } 83 \text { BN TNNT } \\
\text { chu kỳ. }\end{array}$ & $\begin{array}{l}\text { Tỷ lệ rối loạn } \\
\text { là 89,2 \% }\end{array}$ & $19,23 \pm 9,64$ \\
\hline Chúng tôi 2021 & $\begin{array}{c}\text { - } 80 \text { bệnh nhân bệnh thân mạn giai } \\
\text { đoạn cuối ȚNT chu kỳ. }\end{array}$ & Tỷ lệ rối loạn là 80\% & $8(2,25-13)$ \\
\hline
\end{tabular}

Các nghiên cứu trong và ngoài nước đều khẳng định rối loạn dạ dày ruột là phổ biến ở bệnh nhân BTMT giai đoạn cuối cả bệnh nhân TNT và LMB [4],[5],[7]. Kết quả của chúng tôi thấp hơn Lê Xuân Bách và tương đương với các tác giả khác về tỷ lệ tiêu chảy và táo bón. Sau khi thống kê tính điểm GSRS của 80 bệnh nhân BTMT TNT chu kỳ, điểm GSRS trung bình của chúng tôi là 8 điểm, thấp hơn Lê Xuân Bách [6] là 19,28 $\pm 9,47$ điểm. Mức độ biểu hiện của các biểu hiện dạ dày ruột cho thấy, trong 64 bệnh nhân có rối loạn tỷ lệ bệnh nhân rối loạn mức độ nhẹ chiếm $78,8 \%$, vứa chiếm $15 \%$ và chỉ có 6,2\% bệnh nhân rối loạn mức độ nặng. Mức độ rối loạn ở các biểu hiện trào ngược, đau bụng, khó tiêu, tiêu chảy và táo bón cũng chủ yếu rối loạn mức độ nhẹ. Nghiên cứu của Lê Xuân Bách chủ yếu là mức độ vừa. Sự khác nhau này có thể do đặc điểm đối tượng nghiên cứu của chúng tôi khác với đặc điểm đối tượng nghiên cứu của tác giả này. Ở những bệnh nhân suy thận mạn tính giai đoạn cuối lọc máu chu kỳ, các triệu chứng tiêu hoá này được xem là những dấu hiệu chủ quan cho việc lượng giá kết quả của lọc máu. Kết quả nghiên cứu của chúng tôi tỷ lệ bệnh nhân có ít nhất một triệu chứng theo GSRS là 64 bệnh nhân chiếm $80 \%$, số bệnh nhân không có triệu chứng là 16 bệnh nhân chiếm 20\%. Tỷ lệ bệnh nhân có ít nhất 1 triệu chứng tiêu hóa theo GSRS ở có lọc máu là $80 \%$. TheoDong $R$. và cộng sự khi nghiên cứu các triệu chứng tiêu hóa ở bệnh nhân suy thận mạn tính giai đoạn cuối lọc máu chu kỳ và lọc màng bụng, cho kết quả: Tỷ lệ chung của các triệu chứng tiêu hóa, được xác định bởi một GSRS > 1, trong giai đoạn cuối bệnh nhân bệnh thận là 70,7\% (208/294), mà khác nhau giữa các bệnh nhân TNT và $L M B$ (76,4\% so với $61,6 \%, p<0,01)$ [2]. Như vậy kết quả nghiên cứu của chúng tôi phù hợp với các giả về tỷ lệ phần trăm triệu chứng tiêu hóa ở bệnh nhân BTMT giai đoạn cuốiTNT chu kỳ.

2. Liên quan rối loạn dạ dày ruột với một số đặc điểm bệnh nhân: Trong nghiên cứu này chúng tôi thẩy nhóm bệnh nhân tuổi cao có điểm GSRS cao hơn nhóm bệnh nhân tuổi $<60$ có ý nghĩa, $p<0,001$. Kết quả nghiên cứu này giải thích các rối loạn tiêu hoá ở người cao tuổi cao hơn nhóm bệnh nhân tuổi trẻ hơn, do liên quan đến giảm chức năng ruột cũng như giảm tiết các tuyến tuy ngoại tiết. Đặc biệt điểm GSRS có tương quan tương quan nghịch với nồng độ hemoglobin và albumin máu, hệ số tương quan lần lượt là $r=-0,252$ và $-0,49, p<0,05$. Viêm và suy dinh dưỡng là hai yếu tố thường xuất hiện và liên quan với nhau ở bệnh nhân TNT chu kỳ. ở những bệnh nhân đang chạy thận nhân tạo, 
tình trạng viêm mạn tính và suy dinh dương là những yếu tố quan trọng làm suy giảm khả năng miễn dịch. Mối quan hề chặt chẽ giữa suy dinh dưỡng, viêm nhiễm và xơ vữa đông mach ở bênh nhân lọc máu cho thấy sự hiện diện của hội chứng suy dinh dưỡng, viêm và xơ vữa động mạch, có liên quan đến tỳ lệ tử vong cao. Giảm albumin máu vấn là dấu hiệu lâm sàng tốt nhất của suy dinh dưỡng nhưng sự hiện diện của tình trạng viêm nhiễm có thể là một yếu tố tiên lượng mạnh mẽ hơn cho các rối loạn dạ dày ruột cũng như nguy cơ tử vong [8].

\section{KẾT LUÂ̂N}

- Điểm GSRS trung bình là $8(2,25$ - 13), có $80 \%$ bệnh nhân xuất hiện ít nhất 01 triệu chứng dạ dày ruột.

- Nhóm bênh nhân tuổi $\geq 60$; lọc máu $\geq 10$ năm có chỉ số GSRS trung bình cao hơn nhóm không có đặc điểm trên, $p<0,01$. Có mối tương quan nghịch điểm GSRS với nồng độ hemoglobin và albumin máu, $\mathrm{p}<0,01$.

\section{TÀI LIẸU THAM KHẢO}

1. Usta M, Ersoy A, Ayar $Y$, et al. (2020). Comparison of endoscopic and pathological findings of the upper gastrointestinal tract in transplantcandidate

patients undergoinghemodialysis or peritoneal dialysis treatment: a review of literature. BMC Nephrol. 21(1):444.

2. Dong R., Guo ZY, Ding JR, et al. (2014). Gastrointestinal symptoms: a comparison between patients undergoing peritoneal dialysis and hemodialysis. World ] Gastroenterol. 20(32): 11370-5.

3. Esteve Simo V, Moreno-Guzmán $F$, Martínez Calvo G, et al. (2015). Administration of calcimimetics after dialysis: same effectiveness, better gastrointestinal tolerability.Nefrologia. 35(4):403-9.

4. Daniels G, Robinson JR, Walker $C$, et al. (2015). Gastrointestinal symptoms among African Americans undergoing hemodialysis. Nephrol. Nurs. J. 42 : 539-49.

5. Mitrovic M, Majster Z. (2015). The prevalence, severity and diversity of gastrointestinal symptoms in hemodialysis and peritoneal dialysis patients. Nephrol. Dial. Transplant. 30: SP706.

6. Lê Xuân Bách, Lê Việt Thắng, Hoàng Cao Sạ (2015). Khảo sát đắc đđiểm rối loạn tiêu hoá bằng thang điểm đánh giá tỷ lệ triêu chứng da dày ruột ở bệnh nhân suy thận mạn tính giai đoạn III-IV̀. Tap chí Y Dược hoc Quân sứ, số 40: 43-48.

7. Zuvela J, Trimingham C, Leu RL, et al. (2018). Gastrointestinal symptoms in patients receiving dialysis: A systematic review. Nephrology 23: 718-727.

8. Carrera-Jiménez $D$, Miranda-Alatriste $P$, Atilano-Carsi $X$, et al. (2018). Relationship between Nutritional Status and Gastrointestinal Symptomsin Geriatric Patients with EndStage Renal Disease on Dialysis. Nutrients. 10(4):425.

\title{
MỐI TƯƠNG QUAN GIỮA CÁC CHỈ SỐ NHÂN TRẮC VÙNG XƯƠNG MŨI TRÊN THI THỂ NGƯỜI VIẸTT TRƯỞNG THÀNH
}

\author{
Hồ Nguyễn Anh Tuấn*, Võ Văn Hải**, \\ Cao Nguyễn Hoài Thương*, Phạm Đăng Diệu*
}

\section{TÓM TẮT}

Muc tiêu: Xác định kích thước trung bình của các chỉ số nhân trắc trên xương mũi và mối tương quan giữa các kích thước này với nhau. Phương pháp: Nghiên cứu cắt ngang khảo sát xương mũi từ xác ướp formalin $10 \%$ của người Viêtt trưởng thành, tai bộ môn Giải phẫu Trường Đại học y khoa Phạm Ngọc Thạch từ tháng 05/2019 đến tháng 01/2021. Sử dụng phương pháp đo trực tiếp các chỉ số nhân trắc trên xương mũi, các chỉ số sẽ được đo 2 lần và lấy kết quả trung bình giữ̃̃a 2 lần đo. Kết quả: Nghiên cứu khảo sát được 33 mẫu xương mũi, với 45,5\% là nữ, độ tuổi dao động từ $20-87$ tuổi, với tuổi trung bình là 65 tuổi.Các kích

*Trường Đại học Y khoa Phạm Ngọc Thạch

**Đai hoc Y Dước TP Hồ Chí Minh

Chiu trcachs nhiệm chính: Hồ Nguyễn Anh Tuấn

Email: hnat503@pnt.edu.vn

Ngày nhận bài: 26/3/2021

Ngày phản biên khoa học: 10/5/2021

Ngày duyệt bài: 22/5/2021 thước nhân trắc của xương mũi đo được như sau: chiều rộng xương mũi trên là $10,21 \pm 2,53 \mathrm{~mm}$; chiều rộng xương mũi dưới là $17,08 \pm 2,08 \mathrm{~mm}$; đoạn hẹp nhất của xương mũi có kích thước trung bình là $8,24 \pm$ $1,58 \mathrm{~mm}$. Đoan hẹp nhất của xương mũi đa số nằm trên khóe mắt trong và nằm ngang hoăc dưới điểm $S$. Chiều dài xương mũi $(N-R)$ trung bình là $23,81 \pm$ $2,94 \mathrm{~mm}$. Nghiên cứu tìm thây mối tương quan giữa độ rộng xương mũi trên với đoạn hẹp nhất của xương mũivà mối tương quan giữa khoảng cách từ điểm $\mathrm{N}$ đến điểm $S$ với khoảng cách từ điểm $S$ đến điểm $R$. Kết luân: Khi tiến hànhphâ̂u thuật thẩm mỹ mũicần cân nhẳc đến mối tương quan giữa các kích thước xương mũi, nhằm tao đước môt chiếc mũi cân đối, tự nhiên, giảm thiểu biến chứng phẫu thuật và nâng cao sự hài lòng của bênh nhân.

Tư khóa: Nhân trắc mũi, kích thước xương mũi, phẫu thuật tạo hình mũi, nasion, sellion, rhinion

\section{SUMMARY \\ THE CORRELATION BETWEEN THE ANTHROPOMETRIC INDICATORS OF THE}

